\title{
Survey of Hospital Solid Waste Management in North of Iran
}

\author{
Zahra Namvar ${ }^{1}$, Hosseinali Asgharnia ${ }^{1}$, Hourieh Fallah ${ }^{1}$, Abdoliman Amouei²* \\ ${ }^{1}$ Department of Environmental Health Engineering, School of Health, Babol University of Medical Sciences, Babol, \\ Iran. ${ }^{2}$ Department of Environmental Health Engineering, Social Determinants of Health (SDH) Research Center, \\ Babol University of Medical Sciences, Babol, Iran.
}

\begin{abstract}
Background and Objectives: Disposal of hospital waste is a significant environmental concern, particularly in developing regions of the world. Addressing this challenge relies on availability of detailed data on the current status of waste management. Mazandaran Province is located in southern coast of the Caspian Sea and thus its environmental status may directly influence the environment of this Sea. The present study aimed to characterize the situation of hospital solid waste management in this province.
\end{abstract}

Methods: The solid waste management of 40 hospitals of various types was surveyed. Data were collected by a researcher-made questionnaire and summarized using descriptive statistical methods.

Findings: Mean per capita of infectious, general, sharp, and total wastes, was found to be $0.95,1.59,0.06$, and $2.61 \mathrm{~kg} / \mathrm{bed} /$ day, respectively. A total of $36.1 \%$ of all waste is hazardous waste (infectious and sharp wastes). The distance between the temporary place of waste and the nearest hospital ward is $<20 \mathrm{~m}$ in $15 \%, 20-50 \mathrm{~m}$ in $52.5 \%$, $50-100 \mathrm{~m}$ in $12.5 \%$, and $>100 \mathrm{~m}$ in $20 \%$ of the hospitals. This time of waste residence is $<1$ day in $42.5 \%, 1$ day in $37.5 \%$, 2 days in $12.5 \%$, and 1 week in $7.5 \%$ of hospitals. The type of temporary place of waste was a roofed concrete chamber, a metal container, an outdoor area, and a tightly-closed plastic container, respectively, in $82.5 \%, 10 \%, 5 \%$, and $<1 \%$ of the hospitals. The infectious waste is incinerated in $57.5 \%$, autoclaved/hydro-calved in $35 \%$, and disposed untreated in $<1 \%$ of hospitals. Infection control training courses are held every month in $27.5 \%$, every three months in $12.5 \%$, every 6 months in $40 \%$, and once a year in $17.5 \%$ of the hospitals.

Conclusions: A large volume of the total hospital waste is hazardous waste. Disposal of waste in more than half of the hospitals take one day or more. The environmental and health risk associated with this situation calls for appropriate measures. More than half of the surveyed hospitals treat their waste by incineration which may release considerable amounts of air pollutants. Equipping these hospitals with autoclave and hydro-clave devices is thus significant to protection of the environment.

Keywords: Waste management, Medical waste disposal, Solid waste, Hazardous waste

\section{Background and Objectives}

Continuous development of health systems and the growing access of community to medical centers have resulted in escalating production of healthcare-related waste. Hospital waste often contains infectious and/or poisonous materials whose contact with soil, water, and air will contaminate environment. ${ }^{1}$ Pollution of environment by hospital waste is a potential source of prevalence of various types of diseases and epidemics. Thus, professional management of hospital waste is crucial to provide, maintain, and promote public health. ${ }^{2,3} \mathrm{~A}$ basic prerequisite to

${ }^{*}$ Corresponding Author: Abdoliman Amouei, Research Center for Socia Determinants of Health (SDH), Department of Environmental Health Engineering, Babol University of Medical Sciences, Babol, Iran. Tel: +98 1122334366, Fax: +98 1122334367, Email: iamouei1966@gmail.com design and implement a professional hospital waste management is appropriate differentiation of various types of waste. Given the wide range of solid waste produced by hospitals, ${ }^{4,5}$ there are different views on ideal separation of dangerous hospital waste. ${ }^{6,7}$ Generally, the waste produced by health and medical centers are be divided into 2 groups of general waste and hazardous waste. ${ }^{8}$ Typical hospital hazardous waste includes infectious, pharmaceutical, radioactive, and poisonous-chemical materials which according to a World Health Organization (WHO), hazardous for $15 \%$ of total hospital waste. ${ }^{9}$ Depending on the health services provided by a hospital, the amount of hazardous waste, however, may reach up to $90 \%$ of total medical waste. ${ }^{10}$ 
Based on recent statistics from Iran, 450 tons of hospital waste is produced on a daily basis. Also, the average per capita production rate of hospital waste has been estimated to range within $2-9 \mathrm{~kg} / \mathrm{bed} / \mathrm{day}$, whereas the same rate is limited to $2-6 \mathrm{~kg} / \mathrm{bed} /$ day in European countries. ${ }^{11} \mathrm{De}$ spite the need for information on medical waste management for relevant policy-making, the data on equipment, skills, and practices related to hospital waste treatment and disposal in Iran is scarce. While through nationwide studies supported by the government is required in this regard, local data obtained from academic studies may contribute to fill this gap. Thus the present study was designed to gain insight into production and management of solid waste in a sample of health care centers from Mazandaran province (Northern Iran).

\section{Methods}

This descriptive cross-sectional study was carried out in 40 hospitals of Mazandaran province. Data was collected using a researcher-made questionnaire asking about generation, type, transport, temporary storage, and disposal of waste and provision of training courses for the staff and managers. The validity and reliability of this questionnaire were confirmed by the number of faculty members of Babol University of Medical Sciences. All analyses were carried out by SPSS version 19 software package.

\section{Results}

Among 40 surveyed hospitals, 5 (12.5\%) are affiliated to the Social Security Organization, 7 (17.5\%) are private and $33(82.5 \%)$ are public, $6(15 \%)$ are teaching, 7 hospitals $(17.5 \%)$, specialized, and $22(55 \%)$ general.

\section{Generation Rate of Solid Wastes}

Table 1 shows the rate of waste production, based on the type of waste and hospital.

As seen, $34.2 \%, 63.9 \%$, and $1.9 \%$ of waste in the surveyed hospitals are infectious, general, and sharp waste, respectively. The total percentage of hazardous waste (infectious and sharp waste) is equal to $36.1 \%$.

Table 2 shows the mean per capita production rate of infectious, general, sharp, and total waste. The mean per capita of hospital waste production for inpatients and outpatients is given in Table 3.

\section{Waste Storage Places}

The distance between the temporary place of waste storage and the nearest ward (laboratory, pathology, and infectious disease) was less than $20 \mathrm{~m}$ in 6 hospitals (15\%), $20-50 \mathrm{~m}$ in 21 hospitals (52.5\%), 50-100 $\mathrm{m}$ in 5 hospitals $(12.5 \%)$, and more than $100 \mathrm{~m}$ in 8 hospitals $(20 \%)$. The type of temporary place of waste was a roofed concrete chamber, a metal container, an outdoor area, and a tightly-closed plastic container, in 33, 4, 2, and 1 hospital(s), respectively.

\section{Storage Duration}

Depending on the amount of waste produced and the distance of temporary disposal site, waste storage time was different among hospitals. The duration of waste storage was found to be less than 1 day in $42.5 \%, 1$ day in $37.5 \%$, 2 days in $12.5 \%$, and 1 week in $7.5 \%$ of hospitals.

\section{Waste Disposal Method}

Table 4 shows the method used for disposal of infectious waste. As seen $57.5 \%$ of hospitals incinerate the hazardous waste, $35 \%$ perform disinfection using autoclave and hydro-clave. Hospitals which lack incinerator and disinfection devices transfer their infectious waste to another hospital or incinerate it in an outdoor place.

Infection control training courses are held every month in 11 hospitals, every 3 months in 5 hospitals, every 6 months in 16 hospitals, and once a year in 7 hospitals. Only one of the surveyed hospitals offers no training on infection control to its staff and managers.

Table 2. The Mean Per Capita of Infectious, General, Sharp, and Total Wastes Per Bed

\begin{tabular}{lc}
\hline Type of Waste & Per Capita Production $(\mathbf{k g} / \mathbf{b e d} / \mathbf{d})$ \\
\hline Infectious waste & 0.95 \\
General waste & 1.6 \\
Sharp waste & 0.05 \\
Total waste produced & 2.6 \\
\hline
\end{tabular}

Table 1. The Rate of Waste Production, Based on the Type of Waste and Hospital

\begin{tabular}{|c|c|c|c|c|}
\hline \multirow{2}{*}{ Type of Hospital } & \multicolumn{4}{|c|}{ Type of Waste } \\
\hline & General Waste (kg/d) & Infectious Waste $(\mathrm{kg} / \mathrm{d})$ & Sharp Waste (kg/d) & Total Waste Produced $(\mathrm{kg} / \mathrm{d})$ \\
\hline Social Security & 546 & 350.5 & 23 & 930 \\
\hline Private & 593 & 463 & 66.6 & 1122 \\
\hline Public & 5981.5 & 3571.5 & 135.4 & 9869 \\
\hline Total & 7120.5 & 4385 & 225 & 11921 \\
\hline
\end{tabular}


Table 3. Mean Per Capita of Hospital Waste Per Inpatient and Outpatient

\begin{tabular}{lcccccccc}
\hline \multirow{2}{*}{$\begin{array}{l}\text { The Mean Per Capita Waste } \\
\text { Production (kg/d) }\end{array}$} & \multicolumn{2}{c}{ Infectious Waste } & \multicolumn{2}{c}{ General Waste } & \multicolumn{2}{c}{ Sharp Waste } & \multicolumn{2}{c}{ Total Wastes } \\
\cline { 2 - 10 }$y$ & $\%$ & No. & $\%$ & No. & $\%$ & No. & $\%$ & No. \\
\hline Per inpatient & 3 & 71.4 & 5.9 & 74 & 0.15 & 75 & 9.10 & 74 \\
Per outpatient & 1.2 & 28.6 & 2.1 & 26 & 0.05 & 25 & 3.30 & 26 \\
Total & 4.2 & 100 & 8 & 100 & 0.20 & 100 & 12.40 & 100
\end{tabular}

Table 4. Hazardous Waste Disposal Methods

\begin{tabular}{lcc}
\hline Methods of Waste Disposal & No. of Hospitals & $\%$ \\
\hline Incinerator & 23 & 57.5 \\
Autoclave and hydro-clave & 14 & 35 \\
Lack of equipment disposal & 3 & 7.5 \\
\hline
\end{tabular}

\section{Discussion}

The aim of the present study was to survey the rate, types, and disposal of hospital waste in a sample of health facilities of Mazandaran province. More than one-third of waste in the surveyed hospitals was found to be infectious and the total percentage of hazardous waste (infectious and sharp wastes) reached to $36.1 \%$, falling close to the lower bound of the amount of hazardous waste in Iran reportedly varies in the range of 30 to $53 \% .^{12-14}$ Thus the relative volume of hazardous waste in our surveyed hospitals falls close to the lower bound of this range. Nonetheless, this amount goes beyond the range of $10 \%-25 \%$ reported from some developed countries. ${ }^{12}$ The average relative volume of hazardous waste in our hospitals is higher than that reported from South Africa $(8.94 \%)^{15}$ and Libya $(28 \%)^{16}$ and lower than that reported from Egypt (38.9\%). ${ }^{17}$ The difference may be justified by factors such as the hospital specialty and type of services, number of active beds, hospital management, hospital location, and cultural and economic status of the community. ${ }^{18-20}$

The mean per capita of infectious and sharp waste in the present study was $1 \mathrm{~kg} /$ day/bed. Previous studies have reported the average per capita of hazardous waste to vary between 0.67 to $4 \mathrm{~kg} /$ day/bed. ${ }^{12-14,21,22}$ Again this variable approaches to its lower bound in the surveyed hospitals. Nonetheless, lower amount of per capita hospital hazardous waste production has been reported from Brazil $(0.57 \mathrm{~kg} / \text { day } / \mathrm{bed})^{23}$ and Taiwan (0.19-0.88 kg/day/ bed). ${ }^{24}$

In $85 \%$ of hospitals surveyed, the distance between the temporary place of waste and the nearest hospital ward was more than $20 \mathrm{~m}$. In addition a majority of hospitals $(52.5 \%)$ store their waste temporarily $20-50$ m away from hospital wards. Reports from a number of hospitals surveyed in Iran show the corresponding distance varies between 10 to $30 \mathrm{~m},{ }^{25,26}$ which is consistent with our observation. The place of temporary waste storage is directly associated with the environmental and health risk. ${ }^{14}$ Thus, in order to prevent infection and disease transmission the waste should be disposed at the utmost distance from hospital wards especially infectious diseases and surgery operation wards.

While more than $40 \%$ of the inspected hospitals took less than 1 day to remove the waste from temporary storage site, this duration was 1 day in more than one-third, and 2 days or higher in one-fifth of the hospitals. A comparable proportion of teaching hospitals in Tehran also remove their waste in less than 24 hours. ${ }^{25}$ However, the proportion was found to be higher among private hospitals in the same study. ${ }^{25}$ Duration of temporary waste storage in the temporary disposal place is a significant waste management issue which may be improved by appropriate training of the staff. ${ }^{14}$

While the more than half of the surveyed hospital incinerated their waste, only around one-third of them used autoclave and hydro-clave for waste disinfect, and the rest lacked equipment for professional waste disposal. Similarly, Habibzadeh et al ${ }^{26}$ reported $50 \%$ of hospitals situated in 3 Western Iranian cities (Bookan, Mahabad, Saqqez, and Myandoab) to use incinerator for infectious waste handling. Our result together with those from previous reports indicates that incinerator is the most popular method for waste disposal/treatment in Iran. Given the environmental pollution risks associated with this method, application of more advanced and environmental friendly approaches such as autoclave and hydro-clave should be encouraged. Also modern hospital waste management requires separation of waste based on their types to choose the most appropriate pre-disposal treatment method. Facilitating the access to the disinfection equipment was shown to be effective in promotion of this method. ${ }^{14,26}$ Evidence also shows the positive impact of training on improvement hospital waste management. ${ }^{27}$

\section{Conclusions}

A large volume of the total hospital waste is hazardous waste. Disposal of waste in more than half of the hospitals takes one day or more. The environmental and health risk associated with this situation calls for appropriate measures. More than half of the surveyed hospitals treat their 
waste by incineration which may release considerable amounts of air pollutants. Equipping these hospitals with autoclave and hydro-clave devices is thus significant to protection of the environment.

\section{Competing Interests}

The authors declare no competing interests.

\section{Authors' Contributions}

The authors contributed equally to this work.

\section{Acknowledgments}

This article is the result of a research project with the code 9031626 , which supported by the vice chancellor of research and technology of Babol University of Medical Sciences.

\section{References}

1. Ferdowsi A, Ferdosi M, Mehrani Z, Narenjkar P. Certain hospital waste management practices in Isfahan, Iran. Int $\mathrm{J}$ Prev Med. 2012;3(Suppl 1):S176-S185.

2. La Grega M, Buckinham Ap, Aevans J. Hazardous Waste Management. 2nd ed. New York: McGraw-Hill; 2001.

3. Verma LK, Mani S, Sinha N, Rana S. Biomedical waste management in nursing homes and smaller hospitals in Delhi. Waste Manag. 2008;28(12):2723-2734. doi:10.1016/j. wasman.2007.12.013.

4. Joshua IA, Mohammed S, Makama JG, et al. Hospital waste management as a potential hazard in selected primary healthcare centres in Zaria, Nigeria. Nigerian Journal of Technology. 2014;33:215-221.

5. Mohseni A, Javadian M, Yonesian M, Gholami S. Evaluation of collection, transfer and disposal of hospital solids waste government and private hospitals in Mazandaran province in 2001 (Persian). J Mazandaran Univ Med Sci. 2001;11:4552.

6. Muhlich M, Scherrer M, Daschner FD. Comparison of infectious waste management in European hospitals. J Hosp Infec. 2003;55(4):260-268.

7. Koolivand A, Mahvi AH, Azizi K, Binavapour M, Alipour V. Quality analysis and management of health-care waste-products (Persian). Hormozgan Medical Journal. 2009;14:72-79.

8. Eleyan D, Al-Khatib IA, Garfield J. System dynamics model for hospital waste characterization and generation in developing countries. Waste Manag Res. 2013;31(10):986995. doi:10.1177/0734242X13490981.

9. Singh A, Singh J. Quantitative Assessment of Hospital Waste Generation to Recover Energy: A Case Study. In: Khangura S, Singh P, Singh H, Brar G, eds. Proceedings of the International Conference on Research and Innovations in Mechanical Engineering. Lecture Notes in Mechanical Engineering. New Delhi: Springer; 2014.

10. Dehghani M, Kamal A, Changani F, Dehghanifaed E. Quantity and quality of medical wastes in hospitals of Tehran University Medical Sciences in year 2006 (Persian). The Journal of Hakim. 2006;11:40-47.

11. Mohammadian Fazli M, Nassiri J, Nabizadeh R, Mehrasbi M. Qualitative and quantitative assessment and management of hospital waste in Zanjan, Iran in 2011 (Persian). Iran J Health Environ. 2013;6(1):55-64.

12. Taghipour $\mathrm{H}$, Mosaferi M. Characterization of medical waste from hospitals in Tabriz, Iran (Persian). Science of the Total Environment 2009;407:1527-1535.

13. Askarian M, Vakili M. Managing hospital wastes in hospitals affiliated to Shiraz University of Medical Sciences (Persian). Journal of Medical Research. 2003;1:41-51.

14. Bazrafshan E, Kord-Mostafapoor F. Survey of quantity and quality of hospital wastes in Sistan and Balouchestan province, 2008-2009 (Persian). Zahedan Journal of Research in Medical Sciences. 2009;12:26-32

15. Nemathaga F, Maringa S, Chimuka L. Hospital solid waste management practices in Limpopo province, South Africa: a case study of two hospitals. Waste Manag. 2008;28(7):12361245. doi:10.1016/j.wasman.2007.03.033

16. Sawalem M, Selic E, Herbell JD. Hospital waste management in Libya: a case study. Waste Manag. 2009;29(4):13701375.

17. El-Salam A, Magdy M. Hospital waste management in El-Beheira Governorate, Egypt. J Environ Manage. 2010;91(3):618-629. doi: 10.1016/j.jenvman.2009.08.012.

18. Abdulla $F$, Abu Qdais $H$, Rabi A. Site investigation on medical waste management practices in northern Jordan. Waste Manag. 2008;28(2):450-458. doi:10.1016/j. wasman.2007.02.035

19. Yong Z, Gang X, Guanxing W, Tao Z, Dawei J. Medical waste management in China: a case study of Nanjing. Waste Manag. 2009;29(4):1376-1382. doi:10.1016/j. wasman.2008.10.023

20. Birpinar ME, Bilgili MS, Erdoğan T. Medical waste management in Turkey: a case study of Istanbul. Waste Manag. 2009(1);29:445-448. doi:10.1016/j. wasman.2008.03.015

21. Amoui A. Determination of quantity and quality of medical wastes in the hospitals of Babol Medicals Sciences University (Persian). J Babol Med Sci Univ. 2003;4:37-41.

22. Farzadkia $M$, Asgharnia $H$, Rastegar $A$, Gholami $H$. Survey of solid waste management in selected small and large hospitals of Tehran (Persian). Scientific Journal of Ilam University of Medical Sciences. 2014;22:149-157.

23. Da Silva CE, Hoppe AE, Ravanello MM, Mello N. Medical wastes management in the south of Brazil. Waste Manag. 
2005;25:600-605.

24. Cheng YW, Sung FC, Yang Y, Lo YH, Chung YT, Li KC.

Medical waste production at hospitals and associated factors. Waste Manag. 2009;29(1):440-444. doi:10.1016/j. wasman.2008.01.014.

25. Arab M, Ravangard R, Omrani G, Mahmoodi M. Wastes management assessment at public-teaching and private hospitals affiliated to Teheran University of Medical Sciences, Iran (Persian). The Journal of Health Administration. 2010;12:71-77.

26. Habibzadeh S, Adib Hesamy M, Mahmodifar Y. A survey on hospital wastes management In Bookan, Mahabad, Saqqez, and Myandoab-western (Iran-2004). Journal of Health Administration. 2007;9:57-62

27. Windfeld ES, Brooks MSL. Medical waste management-A review. Journal of Environ Manag. 2015;163:98-108. doi:10.1016/j.jenvman.2015.08.013.

Please cite this article as:

Namvar Z, Asgharnia $H$, Fallah $H$, Amouei A. Survey of hospital solid waste management in North of Iran. Int J Hosp Res. 2016;5(2):64-68. doi:10.15171/ijhr.2016.12. 